
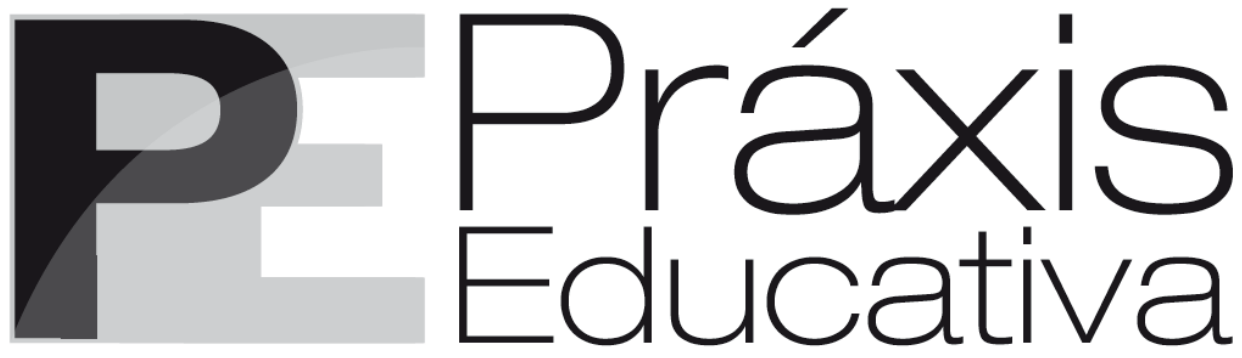

ISSN 1809-4309 (Versão online) DOI: 10.5212/PraxEduc.v.12i3.015

\title{
Mediação verbal para alunos com deficiência intelectual na Sala de Recursos Multifuncionais: reflexões e (pro)posições
}

\section{Verbal mediation for students with intellectual disabilities in the multifunctional resource room: reflections and (pro)positions}

\section{Mediación verbal para alumnos con discapacidad intelectual en el aula de recursos multifuncionales: reflexiones y (pro)posiciones}

\author{
Giovani Ferreira Bezerra*
}

\begin{abstract}
Resumo: Este artigo discute se e como são realizadas práticas de mediação verbal, mediante a oralidade, pelas professoras especialistas que atendem, no contraturno, alunos com deficiência intelectual. O lócus da investigação empírica foi uma Sala de Recursos Multifuncionais (SRM). Tendo por base a Psicologia Histórico-Cultural, recorreu-se à pesquisa participante, com a constituição de grupo colaborativo entre o pesquisador e as professoras. Diário de campo e gravações em áudio dos encontros realizados foram instrumentos de coleta de dados. Verificou-se que as professoras especialistas desenvolvem atividades específicas para contemplar a mediação verbal, mas há necessidade de problematizar suas práticas, tornando os saberes tácitos de suas experiências e de seus saberes teoricamente fundamentados.

Palavras-chave: Pessoa com deficiência intelectual. Desenvolvimento da linguagem. Atendimento Educacional Especializado.
\end{abstract}

Abstract: This article discusses if and how practices of verbal mediation are carried out, through orality, by the specialist teachers who assist, before/after school, students with intellectual disabilities. The locus of empirical investigation was one Multifunctional Resource Room (SRM). Based on the HistoricalCultural Psychology, we have resorted to the participant research, with the constitution of a collaborative group between the researcher and the teachers. Field diary and audio recordings of the held meetings were the data collection instruments. It was found that the specialist teachers develop specific activities to contemplate verbal mediation, but there is a need to problematize their practices, making the tacit knowledge of their experiences and their knowledge theoretically grounded.

Keywords: People with Intellectual Disabilities. Language development. Specialized Educational Service.

Resumen: En el artículo se discute si y cómo se realizan prácticas de mediación verbal, mediante la oralidad, por las profesoras especialistas que atienden en el contraturno a alumnos con discapacidad intelectual. El locus de investigación empírica fue un aula de Recursos Multifuncionales (SRM). Con base en la Psicología Histórico-Cultural, se recurrió a la investigación participante, con la constitución de un grupo colaborativo entre el investigador y las profesoras. El diario de campo y grabación en audio de los

\footnotetext{
* Professor da Universidade Federal de Mato Grosso do Sul (UFMS, campus Navira1́). Doutorando em Educação pela Universidade Federal da Grande Dourados (UFGD). E-mail: <gfbezerra@gmail.com>.
} 
encuentros realizados fueron instrumentos de recolección de datos. Se verificó que las profesoras especialistas desarrollan actividades específicas para contemplar la mediación verbal, pero hay necesidad de problematizar sus prácticas, haciendo los saberes tácitos de sus experiencias y saberes teóricamente fundamentados.

Palabras clave: Persona con discapacidad intelectual. Desarrollo del lenguaje. Atención Educativa Especializada.

\section{Introdução}

Ao longo da primeira década do século XXI, compreendida entre os anos de 2001 e 2010 , vimos oficializar, no Brasil, a proposta de inclusão escolar ampla e irrestrita, pela qual todos os alunos considerados público-alvo da Educação Especial ${ }^{1}$ passaram a ser matriculados nas escolas comuns, independentemente de suas particularidades ontogenéticas. Tanto que, em 2008, após alguns anos de acirrados debates, foi finalmente concluída e lançada, pelo governo federal, a Política Nacional de Educação Especial na Perspectiva da Educação Inclusiva (PNEEPEI). Esta, pelo menos em tese, rechaçou a matrícula de alunos com deficiência, altas habilidades ou transtornos globais do desenvolvimento apenas em escolas ou classes especiais, de forma substitutiva à escola comum. Com isso, observamos a ressignificação do próprio conceito da Educação Especial, a qual deixou de ser um "lugar" bem demarcado para constituir-se, sobretudo, em um suporte ou serviço de apoio à classe comum.

Nesse contexto, o papel básico da modalidade Educação Especial passou a ser o de organizar, fomentar e apoiar a oferta, no contraturno, do Atendimento Educacional Especializado (AEE) aos alunos supracitados, em caráter complementar e/ou suplementar, mas não substitutivo à escolarização na sala de aula comum (BRASIL, 2008). Em publicação subsidiada pelo Ministério da Educação (MEC), Batista e Mantoan (2006, p. 17) explicam que esse "[...] atendimento existe para que os alunos possam aprender o que é diferente do currículo do ensino comum e que é necessário para que possam ultrapassar as barreiras impostas pelas deficiências". Logo, não pode ser confundido com reforço escolar, podendo acontecer tanto em Centros de Atendimento Educacional Especializado (CAEE), devidamente conveniados aos sistemas de ensino, quanto em Salas de Recursos Multifuncionais (SRM), implantadas em escolas públicas comuns pelo Governo Federal (BRASIL, 2008, 2009, 2010, 2011; FÁVERO; PANTOJA; MANTOAN, 2007; GOMES; POULIN; FIGUEIREDO, 2010).

Especificamente no caso dos alunos com deficiência intelectual ${ }^{2}$, as diretrizes do MEC recomendam ao professor especialista, responsável pela organização do AEE na SRM, a proposição de situações-problema e vivências que contribuam para a elaboração do pensamento conceitual, abstrato e simbólico. Dessa forma, as diretrizes mencionadas indicam que o trabalho docente incida "[...] sobre os mecanismos de aprendizagem e desenvolvimento desses alunos" (GOMES; POULIN; FIGUEIREDO, 2010, p. 8). Para a consecução de tal propósito, conforme o último fascículo preparado pelo MEC sobre o assunto:

O acompanbamento na sala de recursos multifuncionais visa, também, à organização da expressão verbal. Desse modo, é importante que o professor organize situações que permitam ao aluno estabelecer diferenças entre as características da língua oral e escrita. O professor do AEE deve proporcionar ao aluno o contato com as mais variadas formas de comunicação, porque

\footnotetext{
1 Considera-se público-alvo da Educação Especial os alunos com deficiência, transtornos globais de desenvolvimento e altas habilidades/superdotação (BRASIL, 2008, 2009, 2011).

2 Atualmente, tem-se empregado, com mais frequência, a denominação deficiência intelectual, nomenclatura recomendada pela Declaração de Montreal, em 2004 (PAN AMERICAN..., 2004). Todavia, nem todos os autores têm incorporado tal designação e, em textos mais antigos, a expressão deficiência mental é prevalecente.
}

Práxis Educativa, Ponta Grossa, v. 12, n. 3, p. 960-979, set./dez. 2017 Disponível em: <http://www.revistas2.uepg.br/index.php/praxiseducativa> 
Mediação verbal para alunos com deficiência intelectual na Sala de Recursos Multifuncionais...

esse contato possibilita o entendimento e a ampliação do seu vocabulário. Ele deve organizar situações em que o aluno seja provocado a se expressar oralmente através de descrições de imagens, fotos, recontos orais e relatos de experiências. (GOMES; POULIN; FIGUEIREDO, 2010, p. 16, grifos nossos).

Destarte, na prática pedagógica do AEE para alunos com deficiência intelectual, ganham destaque as estratégias de mediação semiótica e, particularmente, a da mediação verbal em sentido estrito ${ }^{3}$. Em outras palavras, isso significa que o docente especialista precisa recorrer, sobretudo, à linguagem verbal como elemento mediador entre o seu aluno e os conhecimentos a serem apropriados por este, propondo e desenvolvendo situações dialógicas. Dentre os diversos signos a serem mobilizados no processo de ensino e aprendizagem, em especial nesse caso, a "[...] linguagem oral é um signo por excelência, pois é através dela que expressamos nossas ideias cotidianamente" (CARNEIRO, 2007, p. 33). Muito embora a "[...] capacidade de estabelecer relações entre ações vivenciadas se constitui uma fragilidade do aluno com deficiência intelectual" (GOMES; POULIN; FIGUEIREDO, 2010, p. 16),

[a] oralidade pode possibilitar o desenvolvimento dessa capacidade, permitindo-lhe transitar pelo mundo da representação, porque a palavra substitui o mundo físico dos objetos, ela permite ao sujeito planejar e organizar o pensamento, contribuindo para a compreensão da palavra oral e para a interpretação de significados. A ampliação do vocabulário possibilita o seu uso de modo compreensivo (GOMES; POULIN; FIGUEIREDO, 2010, p. 16, grifos nossos).

Trata-se, pois, de propiciar uma sistemática intervenção docente, mediada pela palavra, não no sentido de "[...] abreviar seu pensamento [do aluno com deficiência intelectual], de fazer por ele ou de aceitar elaborações mais simples. Ao contrário, a intervenção se caracteriza como um momento de mediação intenso que o desafia a ampliar sua estrutura de pensamento" (BRAUN; NUNES, 2015, p. 81). Justifica-se essa prática porque a "[...] mediação, promovendo interações entre o aluno, professor e conhecimento, nas quais o aluno possa expor-se através de formas diversificadas de comunicação construídas na coletividade, pode favorecer $\mathrm{O}$ desenvolvimento de significados e de conceitos mais complexos [...]" (BRAUN; NUNES, 2015, p. 82), em particular nos estudantes com tal deficiência. A fala, nesse contexto, é o meio inicial e basilar pelo qual sentidos e significados podem ser apropriados, partilhados e (re)construídos por esses sujeitos. Afinal, como evidencia Carneiro (2007):

A fala, porém, não é simples articulação de palavras. [...]. A fala não é uma produção do indivíduo, mas uma produção social. [...]. É esse caráter interlocutório da fala que faz dela o lugar de produção de "sentidos". As palavras veiculam "significados" socialmente construídos, possibilitando a comunicação entre os membros de uma mesma comunidade linguística. Entretanto, ao serem enunciadas, elas permitem a emergência de múltiplos sentidos em função da realidade pessoal dos interlocutores e das condições concretas em que ocorre a interlocução. (CARNEIRO, 2007, p. 33, grifos da autora).

Dessa maneira, o professor, que mantém uma relação consciente com a linguagem, estimula a expressão verbal do aluno (BEZERRA; ARAUJO, 2010) e, ao mesmo tempo, direciona "[...] o caminho por onde se desenvolvem as generalizações e o ponto final desse caminho, ou melhor, a generalização daí resultante" (VIGOTSKI ${ }^{4}, 2001$, p. 193). Essa mediação

\footnotetext{
${ }^{3}$ Não se considera, neste texto, toda a amplitude da mediação semiótica, particularizando as reflexões em torno da mediação verbal. Ademais, não se discute, por enquanto, a respeito da linguagem escrita no caso de alunos com deficiência intelectual, dimensão esta que não esteve presente nos objetivos de estudo. Em outro momento, será preciso avançar nesse aspecto.

${ }^{4} \mathrm{O}$ sobrenome desse autor aparece grafado com algumas variações. Assim sendo, no corpo deste texto, em todas as ocorrências, para evitar uma leitura travada e redundante, optou-se pela forma "Vigotski", que vem sendo mais difundida no Brasil. $\mathrm{Na}$ lista final de referências, esse sobrenome aparecerá grafado conforme o material consultado,
}

Práxis Educativa, Ponta Grossa, v. 12, n. 3, p. 960-979, set./dez. 2017 Disponível em: <http://www.revistas2.uepg.br/index.php/praxiseducativa> 
promove "[...] o emprego funcional da palavra ou de outro signo como meio de orientação ativa da compreensão, do desmembramento e da discriminação de traços, de sua abstração e síntese [...]" (VIGOTSKI, 2001, p. 168), operações fundamentais para o domínio de qualquer conceito (BEZERRA; ARAUJO, 2010, 2013). Por isso, a prática da mediação verbal pode significar, para o aluno, o domínio ou a compensação de funções cognitivas, muitas vezes comprometidas pela própria deficiência intelectual, possibilitando-lhe a organização do pensamento verbal e o avanço na produção e na compreensão linguísticas.

Sem negar essas limitações na ontogênese da linguagem nos indivíduos com tal deficiência, o referencial teórico-metodológico da Psicologia Histórico-Cultural traz uma perspectiva superadora, centrada nas possibilidades de desenvolvimento humano. Inicialmente elaborada no começo do século XX por Vigotski (1896-1934) e seus colaboradores, tais como Luria (1902-1977) e Leontiev (1903-1979), essa abordagem revolucionou a Psicologia praticada na então União Soviética. Em vez do foco na deficiência, nas funções psíquicas elementares, nas condições orgânicas e na educação clínico-terapêutica, o grupo de Vigotski buscou alternativas que pudessem compensar o impacto das deficiências na personalidade e superar as limitações biológicas. Para tanto, os pioneiros da Psicologia Histórico-Cultural partiram da compreensão do desenvolvimento humano como um processo social, histórico e cultural, mediado por instrumentos e signos (LEONTIEV, 1978; LURIA, 2007; VIGOTSKI, 1995, 1997).

No bojo dessa perspectiva, a linguagem, considerada em seu aspecto sígnico, constitui-se, portanto, em uma das mais destacadas criações ou "ferramentas" sócio-históricas e culturais da humanidade, do ponto de vista psíquico e cognitivo (BEZERRA; ARAUJO, 2013; LEONTIEV, 1978; LURIA, 2007; VIGOTSKI, 1995, 2001). Tanto que é entendida como uma instância a partir da qual se pode buscar caminhos de compensação social às limitações biológicas que atingem o psiquismo humano (VIGOTSKI, 1997). Por meio dela, as diversas funções psíquicas superiores constituem-se, interpenetram-se e interinfluenciam-se, mediatizando o pensamento verbal. Conforme sintetiza Tuleski (2008, p. 159): “A linguagem, portanto, é fundamental para o desenvolvimento de todas as demais funções e, através do pensamento verbal, transforma todas as outras funções".

Foi com base nessas premissas que a pesquisa ora apresentada ganhou forma, foi proposta e pôde ser desenvolvida, no período de julho de 2013 a junho de 2014, mediante trabalho de campo realizado pelo autor ${ }^{5}$. Na ocasião, buscou-se pesquisar, sob a óptica da Psicologia Histórico-Cultural, se e como ocorria, na única SRM ${ }^{6}$ criada e mantida pela Rede Pública Municipal de Ensino ${ }^{7}$ de um município pequeno, localizado no sul de Mato Grosso do Sul ${ }^{8}$, os

observando-se a percepção de tais variações. Registrá-las é importante para facilitar eventuais buscas pelos textos citados.

5 O projeto de pesquisa intitulava-se A Mediaşão Verbal no Atendimento Educacional Especializado para Alunos com Deficiência Intelectual: contribuicões teórico-metodológicas da Psicologia Histórico-Cultural, tendo se iniciado em julho de 2013, com a aprovação da Pró-Reitoria de Pesquisa e Pós-Graduação (PROPP) da Universidade Federal de Mato Grosso do Sul, pela CI no 2173/2013, de 25 de julho de 2013, e aceite do Comitê de Ética em Pesquisa (CEP) pelo parecer $n^{\circ}$ 675.245, de 4 de junho de 2014. Foi encerrado no começo de 2015.

${ }^{6}$ Essa SRM estava instalada, em espaço próprio, em uma das escolas públicas comuns da Rede Municipal de Ensino (REME), funcionando como sala polo, pois atendia a todos os estudantes dessa rede que precisavam de AEE. No ano de 2015, já com as atividades de pesquisa de campo encerradas, foi aberta outra SRM pela REME.

${ }^{7}$ No município pesquisado, havia, ainda, outras três SRMs em funcionamento, vinculadas, porém, à rede estadual de ensino, não contemplada por este estudo.

8 O citado município apresenta população total estimada em 50.692 habitantes, sendo, portanto, pelos critérios populacionais, considerado pequeno. Disponível em: <http://cidades.ibge.gov.br/xtras/perfil.php?codmun=500570>. Acesso em: 6 set. 2017.

Práxis Educativa, Ponta Grossa, v. 12, n. 3, p. 960-979, set./dez. 2017 Disponível em: <http://www.revistas2.uepg.br/index.php/praxiseducativa> 
processos de interação verbal entre as professoras especialistas e os alunos com deficiência intelectual que frequentavam esse espaço.

Vale ressaltar que, nesta pesquisa, optou-se por focar as discussões em relação à mediação verbal propriamente dita porque interessava compreender como essas professoras promoviam e significavam as interações verbais com os alunos do AEE, basicamente por meio da linguagem oral. Todavia, a mediação verbal é parte de um processo mais amplo de mediação semiótica, isto é, daquela que se dá a partir de quaisquer signos culturais partilhados pelos sujeitos, dentre os quais a linguagem verbal assume destaque, como sugerem os próprios escritos vigotskianos (VIGOTSKI, 1995, 2001, 2010).

Ademais, vários estudos já expressaram, nessa vertente, a relevância dos processos comunicativos e mediações semióticas para o desenvolvimento de sujeitos com deficiências cognitivas (BEZERRA; ARAUJO, 2010; BRAUN, 2012; CARNEIRO, 2007; COSTA, 2006; DAINÊZ, 2009; DIAS, 2010; PADILHA, 2000, 2007, entre outros). Ainda assim, no contexto do AEE, a temática não se esgotou, por serem recentes os trabalhos a respeito das práticas pedagógicas e formas de mediação docente a serem ainda construídas para a oferta desse serviço aos estudantes público-alvo da Educação Especial. Dias (2010, p. 127), ao descrever encontros que organizou com um grupo de professores especialistas para debater e estudar a prática do AEE para alunos com deficiência intelectual, na perspectiva vigotskiana, afirma, por exemplo, que, em sua pesquisa, "[...] não foi possível aprofundar esse tema [o da linguagem como fator de desenvolvimento] [...]". E conclui com a recomendação de que "[...] este é um aspecto do trabalho que precisa de maior investimento conceitual [...]” (DIAS, 2010, p. 127).

Ora, foi justamente esta a intenção desta pesquisa: prosseguir nos estudos e nas práticas que situem a linguagem verbal como instância mediadora do desenvolvimento psíquico de estudantes com deficiência intelectual, atendidos no AEE, segundo as considerações basilares da Psicologia Histórico-Cultural. Por isso, deu-se ênfase à oralidade, por ter como premissa o fato de que, quando essa via é possível e está aberta à intervenção docente, como no caso de alunos com deficiência intelectual, trabalhar sistematicamente com essa modalidade comunicativa é imprescindível para a emergência de funções psicológicas superiores e processos de simbolização do mundo.

\section{Método}

Para a realização desta pesquisa, de natureza qualitativa, pautada no trabalho de campo para coleta de dados, em primeiro lugar, o autor reuniu-se com a coordenadora técnica de Educação Especial do município para apresentar o projeto, já aprovado pela universidade. $\mathrm{O}$ intuito foi obter autorização para frequentar a SRM, agendando, na ocasião, o primeiro encontro com as professoras dessa sala. Autorizado, esse encontro ocorreu no começo de setembro de 2013. A partir de então, sem regularidade muito definida, sempre às sextas-feiras e no período da manhã, realizaram-se, até junho de 2014, encontros com as professoras da citada SRM. Nesse dia, não havia atendimento aos alunos. As professoras reuniam-se, então, para discutir as atividades realizadas na semana e (re)planejamento do seu trabalho. Desse modo, foi possível agregar as reuniões previstas para o desenrolar da pesquisa com as atividades que as docentes já desenvolviam, de forma complementar e articulada.

Desde o começo, as professoras manifestaram interesse pelo projeto apresentado, que consistia em estudar a apropriação e o desenvolvimento da linguagem verbal, sobretudo na modalidade oral, pelas crianças com deficiência intelectual, mediante as contribuições da Psicologia Histórico-Cultural, bem como, em etapa posterior, ainda não realizada, propor e 
direcionar atividades nesse sentido. Nas reuniões realizadas, foram estudados e debatidos alguns textos indicados pelo pesquisador sobre a temática em foco. Ademais, esses textos passaram a ser pautados, também, nas necessidades formativas das professoras, conforme o assunto em grupo era debatido, e elas relatavam suas dificuldades e angústias referentes à prática pedagógica na SRM.

Dessa forma, pode-se dizer que, não obstante as interrupções e demais dificuldades inerentes à pesquisa de campo, constituiu-se, nesse período, um pequeno grupo de estudos com significativo potencial formativo para ambas as partes. Foi emergindo, nessas condições, uma metodologia de pesquisa participante, a qual, como define Severino (2007):

É aquela em que o pesquisador, para realizar a observação dos fenômenos, compartilha a vivência dos sujeitos pesquisados, participando, de forma sistemática e permanente, ao longo do tempo da pesquisa, das suas atividades. O pesquisador coloca-se numa postura de identificação com os pesquisados. Passa a interagir com eles em todas as situações, acompanhando todas as ações praticadas pelos sujeitos. Observando as manifestações dos sujeitos e as situações vividas, vai registrando descritivamente todos os elementos observados bem como as análises e considerações que fizer ao longo dessa participação. (SEVERINO, 2007, p. 120).

Vale ressaltar, todavia, algumas variáveis que interferiram no andamento inicial da pesquisa. Entre elas, destaca-se a alteração no quadro de professoras lotadas na SRM. No ano de 2013, havia, no período matutino, três professoras, sendo uma delas a coordenadora dessa sala, além de uma estagiária de Pedagogia. Posteriormente, em 2014, ao retornar à SRM para continuar os encontros, soube-se que uma dessas professoras havia se mudado de cidade, e a outra fora remanejada para uma classe comum de terceiro ano do Ensino Fundamental. A estagiária, já graduada, assumira outro cargo na Rede Municipal de Ensino. Logo, da formação inicial, apenas a coordenadora permanecia, em companhia de outra professora, que até então nunca havia trabalhado com Educação Especial, mas sim com alfabetização de crianças nas classes comuns. Tais circunstâncias fizeram com que o pesquisador tivesse de reapresentar a pesquisa e a dinâmica de trabalho à nova professora.

No Quadro 1, sintetiza-se o cronograma de encontros, bem como citam-se os textos, com os respectivos autores, que foram estudados durante as sessões de estudo realizadas. A discussão referente aos últimos textos, voltados à organização e à aplicação do plano educacional individualizado, surgiu, sobretudo, da necessidade, manifestada pela professora coordenadora, de rever a forma de trabalho e o AEE ofertado na SRM, tendo por base as necessidades educacionais específicas dos alunos e a proposta de mediação verbal. Até então, trabalhava-se basicamente com projetos, os quais eram (re)adequados às demandas de cada aluno. Para o acompanhamento individual, as professoras usavam, ainda, fichas descritivas, não padronizadas ou sistematizadas na forma de um plano de ensino individualizado, o qual passou a ser construído por elas.

Ainda o Quadro 1 informa quais encontros foram ou não gravados em áudio para posterior transcrição. Deve-se ressaltar que, nas reuniões iniciais, quando o pesquisador estava conhecendo os sujeitos da pesquisa e estes ao pesquisador, optou-se por não gravar e, assim, facilitar a aproximação mútua e diálogo. O mesmo ocorreu quando a nova professora assumiu, em 2014, uma das vagas na SRM, de modo que se buscou primeiro estabelecer contato com ela, para, depois, reiniciar as gravações, estas sempre realizadas com auxílio de um gravador de vOz portátil digital. 
Mediação verbal para alunos com deficiência intelectual na Sala de Recursos Multifuncionais...

Quadro 1 - Cronograma de encontros e procedimentos metodológicos adotados

\begin{tabular}{|c|c|c|}
\hline Encontro & Texto e autoria & Procedimento metodológico \\
\hline $30 / 08 / 2013$ & $\begin{array}{l}\text { Reunião com a representante municipal da } \\
\text { Educação Especial na Gerência Municipal de } \\
\text { Educação. }\end{array}$ & $\begin{array}{l}\text { Não gravado } \\
\text { Anotações em Diário de Campo }\end{array}$ \\
\hline $04 / 09 / 2013$ & $\begin{array}{l}\text { Contato inicial com as professoras especialistas } \\
\text { atuantes na SRM. }\end{array}$ & $\begin{array}{l}\text { Não gravado } \\
\text { Anotações em Diário de Campo }\end{array}$ \\
\hline $27 / 09 / 2013$ & Cultura, mediação e Atividade (MELLO, 2009). & Gravado e transcrito \\
\hline $18 / 10 / 2013$ & $\begin{array}{l}\text { Os princípios do desenvolvimento mental e o } \\
\text { problema do atraso mental (LEONTIEV, 2007). }\end{array}$ & Gravado e transcrito \\
\hline $22 / 11 / 2013$ & $\begin{array}{l}\text { O papel da linguagem na formação de conexões } \\
\text { temporais em crianças normais e 'Oligofrênicas } \\
\text { (LURIA, 2007). }\end{array}$ & Gravado e transcrito \\
\hline $09 / 05 / 2014$ & $\begin{array}{l}\text { Contato com a nova professora da SRM, que } \\
\text { assumira a função no começo de } 2014 \text {, e reunião } \\
\text { para replanejamento dos trabalhos. }\end{array}$ & $\begin{array}{l}\text { Não gravado } \\
\text { Anotações em Diário de Campo }\end{array}$ \\
\hline $23 / 05 / 2014$ & $\begin{array}{l}\text { Discussão sobre plano de ensino individualizado } \\
\text { e formas de acompanhamento pedagógico dos } \\
\text { alunos da SRM a partir dos relatos das } \\
\text { professoras e escolha do aluno para a } \\
\text { intervenção participante do pesquisador, que } \\
\text { não pôde ser realizada. }\end{array}$ & $\begin{array}{l}\text { Não gravado } \\
\text { Anotações em Diário de Campo }\end{array}$ \\
\hline $13 / 06 / 2014$ & $\begin{array}{l}\text { A escolarização de alunos com deficiência } \\
\text { intelectual: uma análise da aplicação do Plano } \\
\text { de Desenvolvimento } \\
\text { Individualizado - } \\
\text { (PLETSCH; GLAT, 2012). }\end{array}$ & Gravado e transcrito \\
\hline $27 / 06 / 2014$ & $\begin{array}{l}\text { Plano Educacional Individualizado: uma } \\
\text { estratégia a ser construída no processo de } \\
\text { formação docente (GLAT; VIANNA; REDIG, } \\
\text { 2012). } \\
\text { Atendimento Educacional Especializado à } \\
\text { pessoa com deficiência intelectual: contribuições } \\
\text { da Psicologia Histórico-Cultural (DAMBRÓS et } \\
\text { al., 2011). }\end{array}$ & Gravado e transcrito \\
\hline
\end{tabular}

Fonte: Elaborado pelo autor.

Todos os encontros gravados foram, portanto, transcritos para análise dos dados, os quais também são provenientes das anotações, das observações participantes e do diário de campo do pesquisador durante suas vistas à SRM e conversas com as professoras especialistas. Elas assinaram o Termo de Consentimento Livre e Esclarecido (TCLE), sendo informadas sobre todas as etapas, autorizações oficiais e andamento da pesquisa, que recebeu anuência dos gestores municipais de educação, nas pessoas da Coordenadora técnica de Educação Especial e do Gerente municipal de educação, bem como aprovação do Comitê de Ética em Pesquisa (CEP). 
Para garantir seu anonimato, como previsto no TCLE, as professoras aparecem identificadas, neste texto, com nomes fictícios, que, arbitrariamente, remetem ao primeiro nome de personalidades e educadoras famosas na história da Educação Especial, como Alice Descoeudres, Helena Antipoff, Maria Montessori, Anne Sullivan e Dorina de Gouvêa Nowill.

O Quadro 2 apresenta as professoras e o pesquisador, o(s) ano(s) em que cada um(a) participou da pesquisa na SRM, considerando o período de 2013 a 2014, e suas respectivas formações naquele momento, possibilitando uma caracterização sucinta dos sujeitos.

Quadro 2 - Caracterização dos sujeitos da pesquisa

\begin{tabular}{|c|c|c|}
\hline Sujeitos & $\begin{array}{l}\text { Período de participação } \\
\text { na pesquisa até } 2014\end{array}$ & Formação \\
\hline Alice (A) & 2013 e 2014 & $\begin{array}{l}\text { Pedagogia } \\
\text { Especialização em Educação Especial } \\
\text { Especialização em Didática } \\
\text { Especialização em Metodologia do Ensino } \\
\text { Superior } \\
\text { Especialização em Psicopedagogia }\end{array}$ \\
\hline Helena $(\mathrm{H})$ & 2013 & $\begin{array}{l}\text { Pedagogia } \\
\text { Especialização em Educação Especial } \\
\text { Especialização em Libras }\end{array}$ \\
\hline Maria (M) & 2013 & $\begin{array}{l}\text { Pedagogia } \\
\text { Especialização em Educação Especial }\end{array}$ \\
\hline Anne (AN) & 2013 & Estagiária do curso de Pedagogia \\
\hline Dorina (D) & 2014 & $\begin{array}{l}\text { Normal Superior } \\
\text { Letras (Língua Portuguesa) } \\
\text { Especialização em Séries Iniciais Especialização } \\
\text { em Educação Infantil } \\
\text { Especialização em Educação Especial (cursada e } \\
\text { concluída ao longo de 2014) }\end{array}$ \\
\hline Pesquisador $(\mathrm{P})$ & $2013-2014$ & $\begin{array}{l}\text { Pedagogo } \\
\text { Mestre em Educação }\end{array}$ \\
\hline
\end{tabular}

Fonte: Elaborado pelo autor.

Apresentados os percursos e os percalços metodológicos deste trabalho de campo, passase, em seguida, à discussão sobre alguns dados obtidos nesse período, considerando o foco do trabalho, qual seja, o recorte da mediação verbal no AEE para alunos com deficiência intelectual. Ressalta-se que, além desse tema gerador, foram exploradas e discutidas outras questões pertinentes à organização e ao funcionamento da SRM, aos critérios de atendimento, de diagnóstico e de avaliação dos alunos recebidos, bem como em relação à prática pedagógica do professor especialista. Todos esses aspectos são relevantes, mas, por ora, não há como abordálos, dada a especificidade e os limites deste artigo. Tais resultados poderão ser apresentados em outras publicações que ainda se espera organizar, com base nos dados já coletados.

\section{Resultados e discussões}

Durante todo o primeiro ciclo da pesquisa, que constituiu na realização desses encontros para estudo e reflexão sobre as práticas como docentes da Educação Especial, as professoras 
relataram, angustiadas, a cobrança que recaía sobre elas - por parte do sistema municipal de ensino, dos professores das classes comuns e/ou das famílias - quanto à necessidade premente de apropriação da leitura e escrita pelas crianças com deficiência intelectual atendidas na SRM. Tal situação comprometia ou desmerecia o desenvolvimento de estratégias de mediação verbal que possibilitassem a emergência de funções psicológicas superiores necessárias à compreensão e ao domínio da leitura e da escrita como prática cultural, logo, com sentido e significado.

Ao transferir-se para esse atendimento a responsabilidade precípua pela alfabetização dos estudantes nessa condição ontogenética, perde-se a oportunidade de promover, no AEE, situações que tornem a escrita e a leitura necessárias aos alunos. Como defende Vigotski (1995, 2008), essas habilidades tornam-se uma apropriação individual mediante a proposição de atividades anteriores, que podem ser entendidas como a pré-história da linguagem escrita, a saber: o gesto como signo social, o jogo simbólico, o desenho representativo e a ampliação das próprias capacidades de comunicação oral dos indivíduos. São essas práticas simbólicas e comunicativas, tipicamente humanas, que possibilitam a emergência da escrita significativa entre as crianças, com ou sem deficiência, com seu ingresso no mundo simbólico.

Nesse ponto, é preciso lembrar também que, para o mesmo autor: "A compreensão da linguagem escrita é efetuada, primeiramente, através da linguagem falada; no entanto, gradualmente essa via é reduzida, abreviada, e a linguagem falada desaparece como elo intermediário" (VIGOTSKI, 2008, p. 141). É por esse motivo que se insiste na importância da mediação verbal, pela via da oralidade, no AEE, como etapa transitória para o domínio de outras habilidades cognitivas e de funções comportamentais complexas. Esse espaço-tempo não pode ser destinado à sistematização acadêmica per se, tampouco tornar-se mera extensão da classe comum. Antes, precisa ser visto como um lugar de apropriação e objetivação da e pela linguagem, no âmbito de suas funções psíquicas superiores, dos e pelos objetos e instrumentos da cultura material, bem como de uso criador e criativo desses instrumentos em práticas sociais, com vistas ao máximo desenvolvimento possível dos sujeitos com deficiência intelectual atendidos (DUARTE, 1993; VIGOTSKI, 1995, 1997, 2008, 2010). Todavia, nem sempre essa tem sido a realidade do AEE, pois, como relata Helena:

Helena $(\mathrm{H})$ : Então, e a gente observa assim, que, às vezes fica sobrecarregado, muita coisa pra nós. A gente vê, por exemplo, assim, que a família traz aqui, deixa o aluno aqui, e espera que a gente faça milagre, né, e, assim, aqui é uma fatia do atendimento que essa criança precisa, pra ela ter um desenvolvimento melhor dentro da inclusão, né. $[\ldots]$

H: [...] a Alice outro dia, lendo um artigo, uma historinha, né [nos momentos de estudo que realizavam antes da pesquisa], a gente repensou aqui muita coisa da questão do $\mathrm{AVD}^{9}$, que, às vezes, a gente é cobrado pra trabalhar com aquela criança [isto é, com deficiência intelectual] a leitura e a escrita. $[\ldots]$

H: E eu vejo assim, nós, professores, no nosso trabalho, a gente ficou condicionado, né. A cobrança assim é tão contínua, tão longa, tão constante, que a gente também perdeu um pouco da visão. (Grifos nossos).

Anne (AN): [...] todo mundo pede, assim, que ensine a ler e a escrever [à aluna que a estagiária acompanha na SRM].

Nesse cenário, diante de tantas outras dificuldades que já enfrenta, é frequente que o professor da classe comum espere uma solução imediata da SRM e dos profissionais que nela atuam, desconsiderando que o trabalho ali realizado é processual e flexível, com uma

${ }^{9}$ AVD, na tradição da Educação Especial, significa Atividade de Vida Diária.

Práxis Educativa, Ponta Grossa, v. 12, n. 3, p. 960-979, set./dez. 2017 Disponível em: <http://www.revistas2.uepg.br/index.php/praxiseducativa > 
temporalidade distinta do calendário escolar, das exigências curriculares e suas classificações. Afinal, a temporalidade visada no AEE é a do próprio aluno, como sujeito da aprendizagem e do desenvolvimento. Essa representação sobre o desenvolvimento humano como muito circunscrito à apropriação de conhecimentos curriculares específicos e habilidades cognitivas isoladas, vistos em si mesmos e de forma pragmática, contamina a forma como o trabalho na SRM é compreendido pelos docentes das classes comuns e mesmo os familiares dos alunos com deficiência intelectual. Consequentemente, quando tentam se distanciar dessa proposta, os docentes da SRM são avaliados negativamente.

Nessas circunstâncias, as atividades de mediação verbal tendem a ser desvalorizadas pelos demais agentes escolares, por não gerar um resultado ou produto imediato, entendidas, muitas vezes, como estratégia para passar o tempo, sem importância. É o que se depreende destes relatos, em que as professoras comentam sobre como sua prática é vista na escola onde atuam na referida SRM:

A: É, não estão fazendo nada, só estão conversando [na SRM].

P: É, e essa conversa que é importante para o desenvolvimento psíquico [...].

H: E essa questão assim...

$[\ldots]$

H: [...] do resultado, né, a gente tem essa cobrança do resultado. Ah! Eu quero ver melhora, eu quero ver progresso, eu quero ver aprendizagem.... $[\cdots]$

AN: [...] então, são progressos [dos alunos atendidos na SRM] que, pra nós, é muito, né, mas, às vezes, as pessoas que estão fora, falam: 'Não faz nada!'. Ninguém sabe!...

Não obstante, as professoras, sob a coordenação de Alice - que atuou durante mais de 20 anos na Associação de Pais e Amigos dos Excepcionais (Apae), diretamente com alunos com deficiência intelectual, nas funções de professora e coordenadora da instituição, de modo que acumula, portanto, a experiência de toda uma carreira docente, constituindo-se em referência para as demais - têm questionado as práticas de AEE, sobretudo a tentativa de se reproduzir, nesse atendimento, características e conteúdos da classe comum. No entender delas, o AEE também deve trabalhar atividades de vida autônoma e social, além de possibilitar algum repertório linguístico-cognitivo e cultural aos estudantes com deficiência intelectual. Do contrário, o resultado pode ser, como relataram, o aprendizado mecânico da leitura e da escrita, ou a fala sem compreensão, como era o caso de alguns alunos que chegavam para ser atendidos por elas.

Diante desse cenário, as professoras não abriam mão de trabalhar algumas Atividades de Vida Diária (AVD) com os estudantes que lhe eram confiados no contraturno, prática característica na tradição da Educação Especial e que, atualmente, tem sofrido muitas críticas, ratificadas nas publicações subsidiadas pelo MEC. De fato, tal prática era muito comum nas escolas especiais, que se pautavam no treino e no condicionamento dos alunos com deficiência intelectual. Todavia, essa crítica deve ser entendida quando as AVDs são cobradas de forma mecânica, repetitiva e descontextualizada, como não parece ser o caso da SRM analisada. Nesse sentido, não se pode confundir o trabalho das professoras em questão com aquele historicamente realizado em muitas instituições educacionais especializadas, as quais, de fato, segundo Batista e Mantoan (2006),

[...] limitaram-se unicamente a treinar seus alunos, subdivididos nas categorias educacionais: treináveis e educáveis; limítrofes e dependentes. Esse treinamento era desenvolvido visando à inserção familiar e social. Muitas vezes, o treino se resumia às 
atividades de vida diária: estereotipadas, repetitivas e descontextualizadas. (BATISTA; MANTOAN, 2006, p. 16).

Ademais, se esse trabalho não puder ser contemplado na SRM, certamente de uma perspectiva crítica e emancipadora, durante o espaço-tempo do AEE, onde ele será realizado, visto que resolver problemas cotidianos da vida diária é, de fato, uma necessidade educacional especial de sujeitos com deficiência intelectual? (PLETSCH, 2009). Nesse sentido, quando começamos os estudos referentes à pesquisa propriamente dita, as professoras já haviam refletido sobre sua prática e se posicionado como autoras de seu fazer pedagógico, resistindo às pressões, às representações e às cobranças do sistema de ensino, por meio da escolha e da valoração de determinadas práticas. Estas, porém, estavam em construção, sem foco em um referencial teórico definido. A proposta de focar a mediação verbal, que lhes foi apresentada, veio, portanto, complementar esse trabalho e subsidiar tais reflexões, com o respaldo teórico-metodológico da Psicologia Histórico-Cultural, o que não significa que passaram a tomá-la como norte exclusivo para as suas ações.

A citada abordagem teórica funcionou, sobretudo, como uma baliza para (re)pensar e sistematizar os trechos do caminho já trilhados. Foi uma janela para suscitar discussões e vislumbrar novas possibilidades e ferramentas conceituais de atuação docente, junto àquelas que já estavam emergindo na SRM, muitas delas quase de forma intuitiva, impelidas pelas demandas do fazer cotidiano. $\mathrm{Na}$ direção do exposto, é ilustrativo o seguinte diálogo que se travou em uma das sessões:

A: Exatamente isso que a gente questiona aqui, né, porque a...Tem algumas crianças aqui que, às vezes, elas até leem alguma coisa, né, só que na hora de você pedir pra ela colocar uma jaqueta, por exemplo, ela não consegue.

P: Não consegue compreender a mediação verbal oral, né.

A: Isto... Quando você pede pra ele explicar o que ele leu, ele não entende o que é que ele leu, então, quer dizer, torna-se uma coisa mecânica...

P: Aham...

A: Né, uma coisa, assim, que não vai... não vai trazer nenhum benefício...

P: Nenhum avanço psicológico..

A: Nenhum avanço psicológico pra ele. Então, aí nós estamos até vendo essa questão, é... E nós estamos pensando até em acrescentar alguns itens de... de vida autônoma aqui pra que a criança...Percebemos [...] que a criança necessita também deste aprendizado. Então, porque, às vezes, nós estamos ensinando a criança a ler ou escrever e, quando você pede pra ela amarrar um cadarço de sapato, ela não consegue. Então, quer dizer, o que que adianta ela saber ler e escrever se não sabe calçar um sapato, não sabe lavar uma mão adequadamente, não sabe escovar um dente, não sabe é...ligar um computador!

P: Usar os instrumentos que ela tem à sua volta, né, os objetos da cultura.

A: Usar os instrumentos. Exatamente!

Assim sendo, no bojo de suas inquietações e de seus desejos de reformulação de sua práxis no AEE, as professoras já vinham se preocupando com a apropriação dos signos e dos instrumentos da cultura pelas crianças com deficiência intelectual em práticas sociais significativas, reservando espaço, em suas atividades rotineiras, para a mediação verbal intencional e contextualizada. Essas ações vão ao encontro da teoria vigotskiana, pois esta considera, entre outras proposições, que a interação humana "[...] depende das práticas 
discursivas e é constituída nelas e por elas, tornando-se, ele mesmo, o uso dos objetos, uma prática discursiva" (PADILHA, 2007, p. 185). E, ainda nessa acepção, “[...] os signos são os mediadores das relações entre os homens, relações estas que constituem esses homens; o uso de signos marca o ser social dos indivíduos e a palavra é o signo por excelência" (PADILHA, 2007, p. 21). Ademais, segundo o próprio Vigotski (2008),

[...] a capacitação especificamente humana para a linguagem habilita as crianças a providenciar instrumentos auxiliares na solução de tarefas difíceis, a superar a ação impulsiva, a planejar uma solução para um problema antes de sua execução e a controlar seu próprio comportamento. Signos e palavras constituem para as crianças, primeiro e acima de tudo, um meio de contato social com outras pessoas. As funçoes cognitivas e comunicativas da linguagem tornam-se, então, a base de uma forma nova e superior de atividade nas crianças, distinguindo-as dos animais. (VIGOTSKI, 2008, p. 17-18, grifos nossos).

No decorrer das sessões de AEE, as docentes percebiam as dificuldades de expressão verbal dos estudantes com deficiência intelectual, as quais, de fato, caracterizam essa condição.

Como bem sintetiza Luria (2007, p. 125): "Os traços que caracterizam a criança atrasada são: distúrbios na participação da linguagem na formação de processos mentais complexos e deficiências nas funções reguladoras e generalizadoras". Essas funções, respectivamente, são referentes à participação da linguagem na organização e no controle da conduta humana e ao pensamento conceitual e abstrato. No trecho a seguir, as professoras manifestam suas percepções a respeito do desenvolvimento da linguagem oral nos estudantes em questão:

\begin{abstract}
A: A gente percebe essa questão na hora que você vai conversar com o aluno. Então, na hora em que você vai conversar, você percebe as respostas curtas, né, às vezes, há uma quebra de fala, né, muda pra outro assunto, então, por quê? Porque ele não tem estabelecido aquele diálogo oral que ele deveria ter, então aí ele fica com uma fala pobre, né. Então, isso aí é uma questão que deveria ser realmente mais trabalhada, porque você falando adequadamente, provavelmente, você vai conseguir a escrita, em seguida, né. Então, nós percebemos isso no aluno que frequenta a sala de recursos sim. Você faz uma pergunta pra ele, e a resposta é breve e, praticamente, monossílaba. Então, essa questão é uma questão que realmente deve ser trabalhada. E a gente está percebendo isso, porque a sala de recursos é recente ainda. A gente tá crescendo $[\ldots]^{10}$.
\end{abstract}

$[\ldots]$

P: E você, Dorina, você tem se deparado agora com essa realidade. Você percebe essa dificuldade?

D: Sim, percebo. Até a Alice falou, agora, que tem aluno monossílabo, que fala uma sílaba só, né, uma frase só...Eu tenho um [aluno] aqui, o Victor ${ }^{11}$, que eu tenho que insistir muito pra ele me dar uma resposta. [...]. Eu tenho que insistir muito pra ele falar alguma coisa comigo.

Diante da percepção dessas dificuldades com a enunciação e a compreensão verbal, as professoras mobilizavam algumas estratégias de intervenção pedagógica que podem iluminar outras práticas e funcionar como ponto de partida para sistematizar seu próprio trabalho, em bases teórico-metodológicas explicitadas e fundamentadas, para além do saber tácito. Pelos seus relatos e mesmo por alguns momentos de observação, pude apurar que as professoras utilizavam, deliberadamente, leitura, contação e discussão de histórias, direcionando perguntas sobre o assunto e solicitando a participação oral das crianças, jogos pedagógicos, sequências lógicas e

\footnotetext{
10 Segundo Alice, essa SRM começou a funcionar no dia 15 de agosto de 2011, conforme anotações no diário de campo do pesquisador.

11 O nome Victor também é fictício, escolhido em alusão a Victor de Aveyron.
}

Práxis Educativa, Ponta Grossa, v. 12, n. 3, p. 960-979, set./dez. 2017 Disponível em: <http://www.revistas2.uepg.br/index.php/praxiseducativa> 
músicas. Além disso, em alguns momentos, optavam por promover atividades em pequenos grupos na SRM, a fim de possibilitar a interação verbal entre os alunos ou estimular o diálogo com eles a partir das situações rotineiras da sala ou do convívio social.

Essas práticas estavam presentes antes do desenvolvimento da pesquisa. Pode-se, então, refletir sobre seu potencial formativo para os alunos com deficiência intelectual à luz das proposições vigotskianas, no sentido de compreender melhor o que já era feito para avançar nesse trabalho, cotejando-o com o referencial teórico adotado. Vale enfatizar, portanto, que havia uma intencionalidade nas falas das professoras em relação ao desenvolvimento linguísticocognitivo dos estudantes atendidos, mesmo que essa intencionalidade não estivesse, ainda, teórica ou claramente formulada. Destacam-se os seguintes relatos que evidenciam as estratégias de mediação verbal empregadas pelas professoras:

AN: Ela [uma aluna cega e que, segundo as professoras, apresentava também um quadro de autismo, possivelmente combinado com deficiência intelectual] gosta bastante de trabalhar, assim, que nós percebemos, que ela tem uma facilidade de aprender é com música, aprende bastante. Ainda bem que a nossa amiga Helena, nessa área, também, ela gosta bastante. Helena trabalha... Nós trabalhamos bastante a música, então, assim, ela desenvolve mais na música e algumas brincadeiras [...].

A: Então, é, até que agora a gente tá percebendo que a contação de história tem contribuído, porque daí, na hora que você conta, você questiona a todos. Então, é uma forma que a gente tá encontrando de tentar fazer ele [o aluno Victor, com deficiência intelectual, mencionado acima por Dorina] se comunicar, porque realmente ele se exime de qualquer resposta. Ele tem assim...É uma questão de se esconder, né. Ele não quer que os outros percebam que ele tem dificuldade na fala, porque ele tem um problema de dicção, devido à deficiência intelectual também. [...]. Então, ele tem dificuldade na fala.

$[\ldots]$

A: Mas nós estamos tentando procurar fazer jogos, né, pra ver se há uma interação maior e uma fala maior entre eles. A questão dos jogos, também das histórias, né, com perguntas orais, para que todos participem. Então, essa é uma forma que a gente, de primeiro momento, encontrou pra tentar superar essas dificuldades, mas não tem sido fácil não, porque a criança, ela não gosta de se expor, né, principalmente quando é na sua dificuldade maior. Então, ela realmente se exime de dar respostas. Então, aí, a gente tá buscando metodologias diferenciadas pra que possa pelo menos sanar um pouco mais essa dificuldade [de expressão verbal], né, pra que o aluno interaja mais com os demais alunos. $[\ldots]$

D: Então, eu procuro trabalhar assim mais em grupo com eles, né, não separadamente, sempre mais em grupos de dois em dois. E o Victor mesmo sempre eu pergunto assim... eu falo com ele assim: Victor, pega isso pra mim. Vai lá, pede pro fulano a caixa de lápis de cor. Eu acho assim que é uma maneira dele estar se socializando mais, que ele vai se comunicando mais.

P: Interessante. É isso que eu acho importante, Dorina, porque, assim, nas nossas...A atividade do professor, a nossa fala é sempre intencional. $[\ldots]$

A: Então, no jogo, a gente também percebe essa questão, porque quando você faz o bingo, por exemplo, no caso, quando você faz o bingo, é uma disputa, né, então, cada um...tem, é: "Não, eu tenho... eu tenho!". Então, é uma forma também de estar interagindo, né? Então, quando tem... o jogo...nós temos o jogo...o Eco...Eco?...

D: Da trilha lá?

P: Ecotrilha?

Práxis Educativa, Ponta Grossa, v. 12, n. 3, p. 960-979, set./dez. 2017 Disponível em: <http://www.revistas2.uepg.br/index.php/praxiseducativa $>$ 
A: Da trilha lá. Então, “Não, é, agora é minha vez!”. Então é uma forma deles estarem interagindo também.

P: É, e nesse caso a linguagem se faz necessária! […].

A e D: Se faz necessária!

Em outra situação, conversou-se sobre o caso de uma aluna com deficiência intelectual, em decorrência de Sindrome de Down, e com traços autísticos, que já estava apresentando progressos significativos em seu desenvolvimento e autonomia, após o ingresso e acompanhamento na SRM. Esse progresso era ratificado pela mãe da criança, de acordo com o depoimento das professoras. O caso é ilustrativo do impacto da mediação verbal na constituição e na ampliação das funções psíquicas superiores, bem como no controle volitivo e na regulação da própria conduta. Perante essas práticas mediadoras, pode emergir o uso racional da linguagem, função psíquica que, muitas vezes, no caso dessa deficiência, se não houver mediação sistemática, pode permanecer no nível da comunicação elementar, emocional e/ou reflexa (LURIA, 2007; VIGOTSKI, 1995, 1997, 2001, 2008).

Segundo o próprio psicólogo bielorrusso, “[...] nos comunicamos com as pessoas em torno de nós, principalmente, com a ajuda da fala. Esse é um dos recursos fundamentais, com a ajuda do qual a criança possui contato psíquico com as pessoas ao seu redor" (VIGOTSKI, 2010, p. 689). Ora, assim sendo, tal afirmação traz à tona algumas implicações pedagógicas, a serem consideradas, pelos docentes, em seu trabalho com as crianças, a fortiori quando se está diante de alunos com deficiência intelectual. Estes, às vezes, mesmo após passada a infância, tiveram poucas chances de participar de vivências comunicativas, de atribuir sentidos e significados aos signos que os cercam, inclusive a palavra falada. Por isso, nessas situações, a abordagem vigotskiana

[...] chama a atenção, em primeiro lugar, para a atitude que os adultos devem ter em relação aos atos de fala com as crianças [e, como proponho, também perante todos os sujeitos/alunos com deficiência intelectual], uma vez que elas não os compreendem como os adultos imaginam. Isso implica na necessidade de uma atitude intencional do professor ou da professora ao conduzir o trabalho educativo, observando mais atentamente as crianças e suas atitudes para perceber os níveis de compreensão dos significados das palavras utilizadas na comunicação oral entre adultos e crianças. Ao mesmo tempo, chama a atenção para a importância do uso intencional da fala para fazer avançar o desenvolvimento do pensamento infantil e o processo de generalização que condiciona a influência da cultura sobre a criança. (MELLO, 2010, p. 732).

De certo modo, as professoras da pesquisa desempenhavam esse importante papel de interlocutoras intencionais, colocando-se, segundo recomendava Vigotski (2010), como referência de linguagem oral mais elaborada para os alunos da SRM, o que lhes permitia apropriar da fala com sentido, significado e intencionalidade. Elas começavam a perceber a necessidade de mediar, pelas práticas discursivas, a constituição das funções planejadora e reguladora da fala nesses alunos (LURIA, 2007; MELLO, 2009, 2010). A seguir, então, o diálogo sobre o caso mencionado, o qual, embora longo, é emblemático:

AN: É, até unha, a mãe falou assim: “Ai, Anne, eu fiz a unha dela tá... a unha dela tá... tá toda...Ela não deixa tirar o esmalte. Aí, ela sentou aqui, eu coloquei a mãozinha dela assim e tirei. Ela foi com a unha pintadinha. A mãe dela [falou]: "Você conseguiu?!” Eu falei: "Conseguil". "Como?!” "Eu fiz isso e isso e isso", que aí é o que, o que a mãe não consegue lá e nós conseguimos, a gente vai transferindo, e a mãe vai usar com ela.

M: Lembra quando a gente dizia: “Ó a mão dela!”?

Práxis Educativa, Ponta Grossa, v. 12, n. 3, p. 960-979, set./dez. 2017 Disponível em: < http://www.revistas2.uepg.br/index.php/praxiseducativa> 
Mediação verbal para alunos com deficiência intelectual na Sala de Recursos Multifuncionais...

AN: É, não podia falar a mão dela, que ela escondia. Agora não, agora ela deixa pegar na mão. O cabelo, não deixava mexer no cabelo. Ela agora escova os dentes sozinha, do jeitinho dela, mas escova...

H: Tudo é questão de ensino, de reforçar esse trabalho.

AN: Agora, nós estamos introduzindo a comida. Só que assim: quatro colheres, não come mais, porque começa a dar ânsia. Aí, a gente para. Então, quando ela tiver mais acostumada, aí, nós vamos estar fazendo: “Ó, agora você vai comer sozinha!". A fala também dela melhorou muito, porque era "sim", "não", "água". Então, você sabia: na hora que ela falava "água”, sabia que ela queria água. Agora, ela fala: "Eu quero água!”. Então, são progressos que, pra nós, é muito, né, mas, às vezes, pras pessoas que estão fora, fala "não faz nada!". Ninguém sabe...

A: É, pra nós que vivemos, né, é visível, mas as pessoas de fora, não acompanharam essa caminhada. $[\ldots]$

AN: Ontem eu conversei com a mãe dela. A mãe dela falou que não sabe o que tá acontecendo. Ela falou assim: "Não sei o que que vocês estão fazendo, mas eu tô adorando, que lá em casa melhorou 100\%!".

H: Que bom!

Marcela: Ela falou assim: "Mas tá falante! Pede as coisas, faz as coisas, às vezes, sozinha!". Aí, eu falei, falei assim, diz que ela levanta. Ontem, diz que ela levantou, levantou não, gritou do quarto: "Eu vou pra escola, eu tô acordada!". Aí, a mãe dela: "Ah, você já tá acordada?!". "Já!” [...].

A: Ela entra das nove às onze [na SRM].

AN: Sete e meia, ela já tava acordada, já gritou: "Eu vou pra escola, eu tô acordada!". Aí, a mãe dela: "Então, levanta". "Eu vou esperar mais um pouquinho e já levanto pra tomar banho". Autônoma, ela falou sozinha!

A: Coisa que não aceitava.

AN: Coisa que não...A mãe falou, a mãe dela falou assim: "Anne, eu não sei o que tá acontecendo, eu tô adorando!”. Falou assim. E, ah!, disse que tem uns dias que ela não tem que vir aqui, que ela levanta querendo vir também, que, por ela, ela vinha todos os dias aqui. Aí, eu falei: “Ah!, que bom né!”. E ela falou: "Nossa, tô adorando!”.

H: É ótimo, porque...

A: É, é aquela questão que ela colocou, né, trabalha-se, mas também respeita-se o momento da criança. Então, você trabalha um pouco, dá uma paradinha, né, deixa a criança um pouquinho à vontade; depois, retoma pra continuar.

M: E trabalha coisa diferente, não só a tarefa.

A: E coisa diferente, não é só a leitura e a escrita.

M: Eles aqui, só a tarefa, eles ficam num estresse.

P: Sim, sim.

A: Não vai! Eles não gostam, eles gostam de um joguinho, do encaixe, de uma historinha, né, de uma conversa. É, até unha tá fazendo aqui, né, passando batonzinho, conversando...

P: Isso, sim, enquanto faz tudo isso, pode conversar, né, com a criança... [...].

$[\ldots]$

Práxis Educativa, Ponta Grossa, v. 12, n. 3, p. 960-979, set./dez. 2017

Disponível em: <http://www.revistas2.uepg.br/index.php/praxiseducativa > 
A: Exatamente! E essa criança é, a qual nós estamos comentando, ela já está indo lá e pedindo, né, na hora do intervalo, e pedindo é... “É sopa!”. Ela pede sopa, porque daí eu... eu pedi pra merendeira, né, pra que ela perguntasse pra ela o que que ela queria, né. Isso é uma forma de tá estimulando ela a falar também. Aí, ela pergunta: "O que que você quer?”. Ela fala: “Eu quero sopa”. Então, quer dizer, já... já é um avanço, né? Quem tá de fora, acha que não é nada, mas, pra nós, é muito significativa essa questão.

P: Com certeza!

A: Né, porque, é, se, por exemplo, daqui a um tempo, ela vai poder tá seguindo sozinha, pegando, né, a alimentação e se virando sozinha.

H: Mas a gente fala: “Ó, vai lá pedir a merenda”. Ela vai sozinha.

AN: Não, diz que ela pega dinheiro e diz que não pode passar ninguém vendendo na rua, que ela pega dinheiro e já para a pessoa, já aborda a pessoa e já compra! Você... quando eu [a mãe] vou ver, "cadê o dinheiro”? "Ah! Mas cadê o dinheiro?!”."Não, eu comprei sorvete”. Então, já é algo que ela tá fazendo sozinha.

P: Sozinha.

AN: Né, diz que não pode passar caminhão de laranja, ela aborda todo mundo!

P: Compra de tudo...

A: É, compra...

P: Mas que é uma prática social, né, que ela consegue participar já, sozinha.

A: É, que ela consegue participar já.

Diante dos relatos expostos, depreende-se a importância que as professoras pesquisadas atribuíam, em várias circunstâncias de sua práxis pedagógica, à comunicação prática e verbal com os alunos atendidos na SRM (LEONTIEV, 1978). Essa preocupação com a mediação verbal era, portanto, constante no desenrolar de suas atividades, o que é imprescindível a todas as crianças, especialmente àquelas com deficiência intelectual. Assim, ao cumprir essa primeira etapa da pesquisa, pôde-se constatar, após quase um ano de trabalho de campo, que essas professoras experimentavam momentos de aproximação entre a teoria e a prática, se considerar-se o que faziam e o que pensavam, conforme objetivado em seus discursos, em relação ao que foi e é preconizado pelos autores da Psicologia Histórico-Cultural. Seu trabalho carece, portanto, de ser ampliado em outros contextos e de ser fortalecido teoricamente.

No entanto, a atuação das professoras, como visto, encontrava resistências do próprio sistema de ensino, descontinuidades pela troca de profissionais e lacunas teórico-metodológicas, que precisarão ser superadas. Porquanto, como considera Mello (2009, p. 366): “A construção de novas práticas a partir da teoria exige estudo, ação e reflexão". Nessa linha de raciocínio, pode-se pensar que os momentos de estudo pelo menos trouxeram referenciais para que essas professoras pudessem justificar e sistematizar seu trabalho, contrapondo-se aos discursos de que nada faziam ou de que deveriam investir imediatamente na leitura e na escrita dos alunos, sem a mediação de outras formas de linguagem. Por isso, espera-se continuar o trabalho em outro momento e com mais envolvidos, ampliando os estudos, as reflexões e as práticas já iniciados, mediante a colaboração de outros professores de SRMs, em que pesem as imprevisibilidades características da pesquisa de campo nesse formato colaborativo.

Práxis Educativa, Ponta Grossa, v. 12, n. 3, p. 960-979, set./dez. 2017 Disponível em: <http://www.revistas2.uepg.br/index.php/praxiseducativa> 
Mediação verbal para alunos com deficiência intelectual na Sala de Recursos Multifuncionais...

\section{Considerações finais}

A pesquisa ora apresentada, não obstante alguns contratempos, possibilitou evidenciar a relevância da mediação verbal, pela via da oralidade, para o desenvolvimento linguístico-cognitivo dos estudantes com deficiência intelectual, enfatizando as funções psicológicas superiores e sua dimensão sígnica. Justamente em relação aos alunos com essa deficiência, pouco se investe na comunicação com eles, por demorarem mais a compreender as situações apresentadas, demandarem mais pistas do interlocutor para a generalização de conceitos e/ou pelas dificuldades de expressão verbal que apresentam.

Apesar disso, com este texto, espera-se ter evidenciado que deixar o aluno com deficiência intelectual alheio à referência das formas mais elaboradas de linguagem verbal agrava ainda mais suas limitações cognitivas e impede que este se constitua como sujeito simbólico nas e pelas práticas discursivas. Ao contrário, a sua participação no diálogo, podendo contar com o apoio e a mediação do outro, possibilita-lhe "[...] fazer previsões de ação - organização do tempo e do espaço que estão postos na cultura. Pensar sobre si, para si e para o outro, dizer as coisas de um certo modo - é a linguagem organizando, comunicando, nomeando, regulando a ação e o pensamento" (PADILHA, 2000, p. 206-207).

Esse é o caminho proposto pela Psicologia Histórico-Cultural para pensar e fazer uma educação, comum e/ou especializada, que prime pelo desenvolvimento humano, em suas múltiplas possibilidades. Assim sendo, em que pesem sua parcialidade, os dados expostos neste artigo são relevantes para o avanço teórico-metodológico da Educação Especial em tempos de inclusão escolar, lançando luz sobre o trabalho a ser realizado no AEE, em SRMs. Em outras palavras, fica a defesa de que a mediação verbal não pode ser, nas atuais circunstâncias, uma preocupação secundária nesse espaço-tempo, mas o ponto de partida da prática docente, no que tange ao atendimento educacional a ser organizado para os alunos com a citada deficiência.

Para além disso, os resultados compilados evidenciaram, ainda, a necessidade de problematizar com professores do AEE as suas práticas, tornando os possíveis saberes tácitos de sua experiência saberes teoricamente fundamentados, conscientes e deliberados. Para tanto, haja vista seu legado conceitual e teórico-prático, a Psicologia Histórico-Cultural pode ser uma importante referência, certamente não a única, neste momento em que se buscam novas propostas e perspectivas para a oferta de AEE. Nessa tarefa, sem dúvida, a universidade tem e terá destacado papel mediador, colaborando com a socialização de conhecimentos e de teorias sintonizados com a humanização do homem, tenha este ou não uma deficiência. Destarte, a pesquisa e o trabalho colaborativos têm uma grande contribuição a prestar nesse sentido.

\section{Referências}

BATISTA, C. A. M.; MANTOAN, M. T. E. Educação inclusiva: atendimento educacional especializado para a deficiência mental. 2. ed. Brasília: MEC/SEESP, 2006.

BEZERRA, G. F.; ARAUJO, D. A. C. Falar é preciso: algumas reflexões sobre o desenvolvimento cognitivo da linguagem em crianças com deficiência intelectual. Interfaces da Educação, Paranaíba, v. 1, n. 2, p. 44-54, 2010.

BEZERRA, G. F.; ARAUJO, D. A. C. Sobre a linguagem: considerações sobre a atividade verbal a partir da Psicologia Histórico-Cultural. Temas em Psicologia, Ribeirão Preto, v. 21, n. 1, p. 83-96, jun. 2013. DOI: 10.9788/tp2013.1-06

Práxis Educativa, Ponta Grossa, v. 12, n. 3, p. 960-979, set./dez. 2017 Disponível em: <http://www.revistas2.uepg.br/index.php/praxiseducativa > 


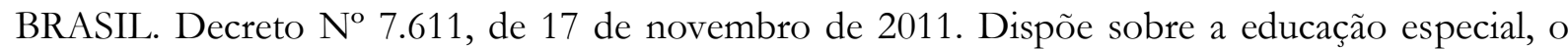
atendimento educacional especializado e dá outras providências Diário Oficial [da] República Federativa do Brasil, Poder Executivo, Brasília, DF, 18 nov. 2011. Seção 1, n. 221, p. 12.

BRASIL. Resolução No 4, de 2 de outubro de 2009. Institui Diretrizes Operacionais para o Atendimento Educacional Especializado na Educação Básica, modalidade Educação Especial. Diário Oficial [da] República Federativa do Brasil, Poder Executivo, Brasília, DF, 5 out. 2009. Seção 1, p. 17

BRASIL. Ministério da Educação. Secretaria de Educação Especial. Política Nacional de Educação Especial na Perspectiva da Educação Inclusiva. Documento elaborado pelo grupo de trabalho nomeado pela portaria n. ${ }^{\circ} 555 / 2007$, prorrogada pela portaria ${ }^{\circ} 948 / 2007$, entregue ao Ministro da Educação em 7 de janeiro de 2008. Inclusão: revista de educação especial, Brasília, v. 4, n. 1, p. 7-17, jan./jun. 2008. (Edição Especial).

BRASIL. Ministério da Educação. Secretaria de Educação Especial. Manual de orien,tação: Programa de Implantação de Sala de Recursos Multifuncionais. Brasília: MEC/SEESP, 2010. Disponível em: $<$ http:/ / portal.mec.gov.br/index.php?option $=$ com_content\&view $=$ article\&id=17430:programaimplantacao-de-salas-de-recursos-multifuncionais-novo\&catid=194\&Itemid=164>. Acesso em: 13 mar. 2015.

BRAUN, P. Uma intervenção colaborativa sobre os processos de ensino e aprendizagem do aluno com deficiência intelectual. 2012. 324 f. Tese (Doutorado em Educação) Universidade do Estado do Rio de Janeiro, Rio de Janeiro, 2012.

BRAUN, P.; NUNES, L. R. d'O. P. A formação de conceitos em alunos com Deficiência Intelectual: o caso de Ian. Revista Brasileira de Educação Especial, Marília, v. 21, n. 1, p. 7592, jan./mar. 2015. DOI: 10.1590/s1413-65382115000100006

CARNEIRO, M. S. C. Deficiência mental como produção social: uma discussão a partir de histórias de vida de adultos com Síndrome de Down. 2007. 193 f. Tese (Doutorado em Educação) - Universidade Federal do Rio Grande do Sul, Porto Alegre, 2007.

COSTA, D. A. F. Superando limites: a contribuição de Vygotsky para a educação especial. Revista Psicopedagogia, São Paulo, v. 23, n. 72, p. 232-240, set./dez. 2006.

DAINÊZ, D. A inclusão escolar de crianças com deficiência mental: focalizando a noção de compensação na abordagem histórico-cultural. 2009. 148 f. Dissertação (Mestrado em Educação) - Universidade Metodista de Piracicaba, Piracicaba, 2009.

DAMBRÓS, A. R. T. et al. Atendimento Educacional Especializado à pessoa com deficiência intelectual: contribuições da Psicologia Histórico-Cultural. Revista Teoria e Prática da Educação, Maringá, v. 14, n. 1, p. 131-141, jan./abr. 2011.

DIAS, M. C. Atendimento educacional especializado complementar e a deficiência intelectual: considerações sobre a efetivação do direito à educação. 2010. 156 f. Dissertação (Mestrado em Educação) - Universidade de São Paulo, São Paulo, 2010. 
DUARTE, N. A individualidade para-si: contribuições a uma teoria histórico-social da formação do indivíduo. Campinas: Autores Associados, 1993.

FÁVERO, E. A. G.; PANTOJA, L. M. P.; MANTOAN, M. T. E. Atendimento Educacional Especializado: aspectos legais e orientações pedagógicas. São Paulo: MEC/SEESP, 2007.

GLAT, R.; VIANNA, M. M.; REDIG, A. G. Plano Educacional Individualizado: uma estratégia a ser construída no processo de formação docente. Ciências Humanas e Sociais em Revista, Rio de Janeiro, v. 34, n. 12, p. 79-100, 2012. DOI: 10.4322/chsr.2014.005

GOMES, A. L. L. V.; POULIN. J. R.; FIGUEIREDO, R. V. A Educação Especial na perspectiva da inclusão escolar: o atendimento educacional especializado para alunos com deficiência intelectual. Brasília: MEC/SEESP; Fortaleza: Universidade Federal do Ceará, 2010. (Coleção A Educação Especial na Perspectiva da Inclusão Escolar, v. 2).

LEONTIEV, A. N. O desenvolvimento do psiquismo. Lisboa: Livros Horizonte, 1978.

LEONTIEV, A. N. Os princípios do desenvolvimento mental e o problema do atraso mental. In: LEONTIEV, A. N. et al. Psicologia e Pedagogia: bases psicológicas da aprendizagem e do desenvolvimento. 4. ed. São Paulo: Centauro, 2007. p. 87-105.

LURIA, A. R. O papel da linguagem na formação de conexões temporais e a regulação do comportamento em crianças normais e oligofrênicas. In: LEONTIEV, A. N. et al. Psicologia e Pedagogia: bases psicológicas da aprendizagem e do desenvolvimento. 4. ed. São Paulo: Centauro, 2007. p. 107-125.

MELLO, S. A. Cultura, mediação e atividade. In: MENDONÇA, S. G. L.; SILVA, V. P.; MILLER, S. (Orgs.). Marx, Gramsci e Vigotski: aproximações. Araraquara: Junqueira \& Marin; Marília: Cultura Acadêmica, 2009. p. 365-376.

MELLO, S. A. A questão do meio na pedologia e nas implicações pedagógicas. Psicologia USP, São Paulo, v. 21, n. 4, p. 727-739, 2010. DOI: 10.1590/s0103-65642010000400005

PADILHA, A. M. L. Práticas educativas: perspectivas que se abrem para a Educação Especial. Educação \& Sociedade, Campinas, v. 21, n. 71, p. 197-220, jul. 2000. DOI: 10.1590/s010173302000000200009

PADILHA, A. M. L. Práticas pedagógicas na educação especial: a capacidade de significar o mundo e a inserção cultural do deficiente mental. 4. ed. Campinas: Autores Associados, 2007.

PAN AMERICAN Health Organization. World Health Organization. The Montreal Declaration on Intellectual Disabilities. Montreal: PAHO; WHO, 2004. Disponível em: <http://www.mdri.org/mdri-web-2007/pdf/montrealdeclaration.pdf>. Acesso em: 21 fev. 2012.

PLETSCH, M. D. Repensando a inclusão escolar de pessoas com deficiência mental: diretrizes políticas, currículo e práticas. 2009. 254 f. Tese (Doutorado em Educação) Universidade do Estado do Rio de Janeiro, Rio de Janeiro, 2009. 
PLETSCH, M. D.; GLAT, R. A escolarização de alunos com deficiência intelectual: uma análise da aplicação do Plano de Desenvolvimento Educacional Individualizado. Linhas Críticas, Brasília, v. 18, n. 35, p. 193-208, jan./abr. 2012.

SEVERINO, A. J. Metodologia do trabalho científico. 23. ed. rev. e atual. São Paulo: Cortez, 2007.

TULESKI, S. C. Vygotski: a construção de uma psicologia marxista. 2. ed. Maringá: Eduem, 2008.

VIGOTSKI, L. S. A construção do pensamento e da linguagem. São Paulo: Martins Fontes, 2001.

VIGOTSKI, L. S. A formação social da mente: o desenvolvimento dos processos psicológicos superiores. 7. ed. São Paulo: Martins Fontes, 2008.

VIGOTSKI, L. S. Quarta aula: a questão do meio na pedologia, Lev Semionovich Vigotski. Psicologia USP, São Paulo, v. 21, n. 4, p. 681-701, 2010. DOI: 10.1590/S010365642010000400003

VYGOTSKI, L. S. Obras escogidas III: historiadeldesarrollo de las funciones psíquicas superiores. Madrid: Visor, 1995.

VYGOTSKI, L. S. Obras escogidas V: fundamentos de defectología. Madrid: Visor, 1997.

Recebido em 19/05/2017

Versão corrigida recebida em 01/09/2017

Aceito em 03/09/2017

Publicado online em 11/09/2017 